\title{
СОЗДАНИЕ ФИНАНСОВОЙ ИНФРАСТРУКТУРЫ КОММЕРЧЕСКИХ БАНКОВ КАК НОВЫЙ СПОСОБ ОРГАНИЗАЦИИ ДЕЯТЕЛЬНОСТИ В СФЕРЕ ЦИФРОВЫХ ТЕХНОЛОГИЙ
}

\section{CREATION OF THE FINANCIAL INFRASTRUCTURE OF COMMERCIAL BANKS AS A NEW WAY OF ORGANIZING ACTIVITIES IN THE FIELD OF DIGITAL TECHNOLOGIES}

I. Vasilev

Summary. Integration and globalization contribute to the modernization and development of the banking system as a whole, which affects the expansion and functionality of possible prospects for building the organization of each bank. With the strategy of innovative development and maintaining competition in the banking sector, banks are constantly developing new banking products, services, processes and technologies, including improving existing ones. In today's environment, our country has significantly increased the role of introducing digital technologies as an effective tool directly to the entire organization of activities within a particular bank, which is relevant at the modern stage. Digital technologies directly influence the formation of the credit organization ecosystem and, as a result, optimization of business processes, lower costs and generally increase competitiveness in the banking sector.

Keywords: information technology, banking technologies, information society development strategy, digital technologies, digital economy.

\author{
Васильев Игорь Иванович \\ К.э.н., дочент, Финансовый университет при \\ правительстве Российской Федерации \\ vasilev-1962@inbox.ru
}

Аннотация. Интеграция и глобализация способствуют модернизации и развитию банковской системы в целом, что отражается на расширении и функциональности возможных перспектив для построения организации деятельности каждого банка.

При стратегии инновационного развития и поддержания конкуренции в банковском секторе банки постоянно разрабатывают новые банковские продукты, услуги, процессы и технологии, в том числе совершенствуют существующие.

В современных условиях нашей страны значительно возросла роль внедрения цифровых технологий как эффективного инструмента непосредственно на всю организацию деятельности внутри конкретного банка, что актуально на современном этапе. Цифровые технологии напрямую влияют на формирование экосистемы кредитной организации и, как следствие, оптимизацию бизнес-процессов, снижению издержек и в целом увеличению конкурентоспособности в банковском секторе.

Ключевые слова: информационные технологии, банковские технологии, стратегия развития информационного общества, цифровые технологии, цифровая экономика.

и воссоединение стандартов взаимодействия всех элементов финансовой инфраструктуры.

Финансовая инфраструктура в банковской системе предполагает существование и достижение результатов цифровизации при сочетании следующих компонентов-платформ:

- для удаленной аутентификации и идентификации; - быстрых платежей;

- маркетплейс для финансовых продуктов и услуг;

- для регистрации финансовых сделок;

- Национальная система платежных карт;

- система передачи финансовых сообщений;

- сквозной идентификатор клиента;

- создание платформы для облачных сервисов;

- на основе технологии распределенных реестров.

Удаленная идентификация позволяет минимизировать количество отделений кредитных организаций, 
издержки на персонал, аренду и обслуживание, потому значительная доля услуг доступна онлайн. Например, в США уже давно активно применяют удаленную идентификацию: Bank of America и Royal Bank по отпечатку пальца, Barclays по сосудистому отпечатку, по лицу, Wells Fargo - либо по голосу и лицо, либо по сосудистому рисунку глазного яблока.

В России, ориентировочно с начала июня 2018 г. в некоторых банках была введена единая биометрическая система, которая была разработана совместно с Ростелекомом по инициативе Министерства цифрового развития, связи и массовых коммуникаций, а также ЦБ РФ. Главное преимущество данной системы:

- возможность осуществления услуг клиентов, которые территориально отдалены от реальных отделений кредитных организаций; обладает следующими принципами - мультимодальность:

- обрабатывает вместе голос и лицо, мультивендорность - открытая платформа, к которой могут присоединиться любые вендоры биометрии;

- liveness - способность отображать «подделку» вместо живого человека;

- выявление аномалий - ЕБС может не только определять мошенников, но и усиливать банковские системы от фрода с помощью машинного обучения;

- безопасность данных.

Данные, который сдает при идентификации операционисту/менеджеру банка привязываются к учетной записи Госуслуг (требуется оригинал паспорта и СНИЛС). Security Operation Center (SOC) «Ростелекома» постоянно мониторит защищенность системы. Биометрические шаблоны хранятся в обезличенной форме в защищенных хранилищах, отдельно от персональных данных, которые находятся и хранятся в базах федеральных органов власти.

С учетом внедрения и развития цифровизации различных сфер повышается требование к прохождению мгновенных платежей между юридическими, физическими лицами. Происходит переформатирование существующих механизмов проведения переводов, снижение межбанковских барьеров, становление усовершенствованной системы быстрых платежей. Данная система предполагает быстрый перевод денежных средств из одного банка в другой банк по номеру телефона. Оператором и расчетным центром выступает Банк России, а операционным и клиринговым центром НСПК. В течение 2019 года подключено половина топ-50 банков.

Глобализация и развитие технологий в настоящее время практически каждый средний-крупный бизнес приводит к возникновению специальной единой платформы, позволяющей покупателям приобретать различного вида продукты или услуги. На данный момент данная платформа называется именно маркетплейсом, что применимо и к банковской сфере. Свои сайты и офисы кредитные организации превращают в данный маркетплейс для продажи как банковских, так и не банковских продуктов, и услуг (например, применимо к Сбербанку, Тинькофф Банку, Альфа-Банку). Как пример - пилотный проект Яндекса, который на базе своей платформы начал продавать банковские продукты Сбербанка, которые наиболее востребованы у населения страны.

Стоит отметить, что 18 октября 2018 года на форумe Finopolis Московская биржа подписала соглашение о сотрудничестве для развития проекта «Маркетплейс» с рядом крупных банков, Национальным Расчетным Депозитарием, инициатором выступал Банк России. Теперь каждое физическое лицо, находясь в любой точке земного шара может видеть в режиме онлайн основные предложения банков, управляющих и страховых компаний; клиент будет иметь свой личный кабинет с индификатором, через который он может управлять своими приобретенными продуктами/услугами.

На первом уровне клиентам будет предоставлен доступ к банковским вкладам, включая возможность одновременной биометрической идентификации. На следующем уровне уже будут доступны различные финансовые ценные бумаги, включая ПИФы, государственные облигации, а также страховые и кредитные продукты (например, ОСАГО и КАСКО). Основное преимущество маркетплейса состоит в трансформации, выходе на новые рынки, снижению издержек на филиальные сети кредитных организаций, улучшение качества предлагаемых продуктов и услуг на базе конкуренции, повышения автоматизации процессов, взаимодействия на единой рабочей платформе.

Формирование маркетплейса - создание и обеспечение безопасной доверенной среды для совершения определенного количества транзакций за операционный день. При таком количестве плюсов есть и существенные недостатки, т.к.для организации полноправной работы маркетплейса требуется изменения законодательства, например, на тему финансового агрегатора, о регистраторе финансовых операций, разработчиков ботов. В настоящее время в Госдуме на рассмотрении находится законопроект [2] о совершении сделок с использованием электронной платформы, который фактически регистрирует условия образования и функционирования маркетплейсов, регулятором будет выступать ЦБ РФ. В данном документе обсуждаются вопросы о регистрации участников, видам сделок, порядке списания 
денежных средств через оператора, объем размещения финансовой информации и пр.

В отдельную категорию формирования финансовой инфраструктуры банка будет включена регистрация и формирование отдельной платформы для регистрации финансовых сделок. Данная платформа, как и маркетплейс создана для в целях развития конкуренции и увеличению организации финансовой доступности. Данная платформа будет включать единый реестр сделок на финансовом рынке, а также единый доступ к данным сделкам. Данный проект пока еще находится на рассмотрении у Банка России. Данный сервис имеет преимущества в удобстве по управлению финансовыми инструментами в течении ограниченного количества времени, консультациям и технологической поддержке на этой платформе, а в перспективе планируется робоэдвайзинг, например, на базе формирования инвестиционного портфеля клиента.

На формирование финансовой инфраструктуры коммерческих банков оказывает большое влияние Национальная система платежных карт «Мир», которая обеспечивает удобство, доступность и безопасность безналичных платежей, бесперебойность проведения внутрироссийских транзакций по банковским картам (клиенты могут спокойно совершать покупки, снимать наличные, оплачивать безналичным путем платежей через терминалы эквайринга, в т.ч. бесконтактно). С 2020 года планируется получение госуслуг не только по своему паспорту, но и при помощи национальной карты. Также для осуществления покупок по карте «Мир» будет применяться биометрия лица, мимика и голос, что повлечет за собой сокращение наличных карт, а значит и снижение рисков мошенничества.

В 2014 году были введены антироссийские санкции со стороны Украины, Европарламент принял резолюцию, где Россию собирались исключить из системы SWIFT (межбанковская система, которая позволяет при наборе определенных правил осуществлять мгновенные переводы между иностранными банками на счета своих клиентов). В связи с этим Банк России в целях безопасности создал свой аналог, который называется системой передачи финансовых сообщений (СПФС) - еще один компонент, звено в создании платформы в системе финансовой инфраструктуры коммерческих банков. Актуальной темой является модернизация СПФС на базе распределенных реестров, т.е. появляется блокчейн-версия данной платформы, которая позволяет гарантировать прозрачность и анонимность всех участников данной цепочки без участия контролирующего органа.

Можно отметить, что у каждого физического лица привязано много информации (например, данные па- спорта, СНИЛС, свидетельства о рождении, ИНН и пр.). Для того, чтобы систематизировать и комплексно привязать все эти данные, в планах ввести так называемый сквозной идентификатор клиента, который будет являться «цифровым паспортом», что вполне применимо на единой платформе для финансовых сделок, маркетплейсе. На данный момент разработкой данного проекта занимается Банк России, Министерство Финансов и Минкомсвязи. Планируется синхронизировать и актуализировать данные граждан и внести изменения с помощью МВД РФ. Ожидается, что в сочетании с биометрией данный идентификатор снизить издержки, повысит эффективность деятельности финансовой, банковской сферы как в России, так и за ее пределами. Например, сквозной идентификатор позволит банковским работникам проверять кредитный рейтинг физического лица и сохранять необходимую информацию о нем на протяжении долгого периода времени.

Немаловажным пунктом для создания единой финансовой инфраструктуры внутри коммерческих банков является применение платформы на базе облачных сервисов. Облачные технологии - особая система, где клиент использует ресурсы (например, оперативная память, сетевые каналы, ПО, процессорное время и пр.), группу сервисов в сети, которые выглядят как единый виртуальный сервер, где клиент может гибко и оперативно менять объемы потребляемых ресурсов.

Кредитным организациям облачные технологии в перспективе можно применять в следующих случаях:

- при анализе данных на мировых рынках, например, на финансовом обрабатывается большой объем информации (без содержания инсайдерской информации), который можно хранить в отдельном облаке;

- для разовых аналитических отчетов в процессе организации деятельности отделов внутри банков, тем самым исключая покупку дополнительной ІТ-инфраструктуры, оптимизируя риск-менеджмент;

- при выявлении мошеннических операций, когда облачный сервис, анализируя стандартные методы поведения клиентов при определении не типичных моделей сразу будет сигнализировать о данном виде операций, сюда можно включить биометрические данные, в т.ч. систему распознавания лиц;

- облачные технологии на базе машинного обучения помогут определять специфику поведения клиентов, например, если будет выявлена тенденция ухода клиента из банка, то будут предприниматься попытки выяснения причин и возврата в целях дальнейшего обслуживания; 
- внедрение облачных технологий отразиться на поддержке сайтов (можно вынести в облако резервный сайт), мобильных устройств (упростят подготовку и отправку любой информации больших объемов);

- в процессе деятельности банков аккумулируется большой объем информации, который также можно хранить в облаке (также дополнительно шифровать и извлекать), например, записи с камер наблюдения, отсканированные документы клиентов (ФЛ и ЮЛ), записи разговоров сотрудников колл-центра, также многие материалы для обучения персонала;

- для разработки и тестирования банковских приложений, в данном случае применяются гибридные облака, которые позволяют воспроизвести возможное поведение данных приложений, гибко управлять ресурсами внутри них.

Технология блокчейн или «технология распределенных реестров» на данный момент пользуется активным спросом и стремительно охватывает банковскую сферу. Ее главная задача заключается в том, что она представляет собой новый способ создания баз данных, где нет единого центра управления, образуя «блочную цепь». Именно блокчейн позволяет обрабатывать транзакции в режиме реального времени, отсутствие посредников в цепочке позволяет сократить издержки на осуществление переводов. Еще одно из самых главных преимуществ технологии блокчейн состоит в смарт-контрактах, которые полностью автоматизируют все платежи, снижают до минимума случаи мошенничества (например, при размещении корпоративных облигаций - компания-эмитент определяет основные параметры контракта, при наступлении передачи облигации владельцу автоматически начинается выплата купонных платежей до тех пор, пока не наступит срок не наступит срок исполнения облигации). Также данная система кардинально изменяет банковскую сферу в сочетании с технологией «Интернета вещей» (оплата ЖКХ, Интернета, парковок и др. реализуются с помощью распределенных реестров с полностью анонимностью и прозрачностью).

Таким образом, финансовая инфраструктура состоит из взаимодополняемых элементов, которые влияют на организацию деятельности каждого коммерческого банка, что увеличивает доступность и конкуренцию финансовых услуг. На данный момент ключевым фактором является система открытых API, т.е. программных интерфейсов приложений, что включает в себя интеграцию сервисов коммерческих банков в рамках ЕАЭС. Планируется открыть информацию через данный сервис о банкоматах, отделениях, услугах для физических и юридических лиц для нерезидентов.

\section{ЛИТЕРАТУРА}

1. Информация Банка России «0сновные направления развития финансовых технологий на период 2018-2020 г.» [7]

2. Текст законопроекта № 617867-7 «0 совершении сделок с использованием электронной платформы»

3. 0 системе управления реализацией национальной программы «Цифровая экономика Российской Федерации» (вместе с «Положением о системе управления реализацией национальной программы «Цифровая экономика Российской Федерации»): Постановление Правительства РФ от 02.03 .2019 № 234 // СПС «КонсультантПлюс» (дата обращения: 17.10.2019)

4. Основные направления развития финансовых технологий на период 2018-2020 годов: Информация Банка России от 16.02.2018 // СПС «КонсультантПлюс» (дата обращения: 17.10.2019)

5. Стратегия повышения финансовой доступности в Российской Федерации на период 2018-2020 гг. (одобрено Советом директоров Банка России 26.03.2018 // СПС «КонсультантПлюс» (дата обращения: 17.10.2019) 